This item was submitted to Loughborough's Research Repository by the author.

Items in Figshare are protected by copyright, with all rights reserved, unless otherwise indicated.

\title{
Bad behaviour or societal failure? Perceptions of the factors contributing to drivers' engagement in the fatal five driving behaviours
}

PLEASE CITE THE PUBLISHED VERSION

https://doi.org/10.1016/j.apergo.2018.08.008

\section{PUBLISHER}

(c) Elsevier

VERSION

AM (Accepted Manuscript)

\section{PUBLISHER STATEMENT}

This paper was accepted for publication in the journal Applied Ergonomics and the definitive published version is available at https://doi.org/10.1016/j.apergo.2018.08.008.

\section{LICENCE}

CC BY-NC-ND 4.0

\section{REPOSITORY RECORD}

Salmon, Paul M., Gemma Read, Vanessa Beanland, Jason Thompson, Ashleigh J. Filtness, Adam Hulme, Rod McClure, and lan Johnston. 2019. "Bad Behaviour or Societal Failure? Perceptions of the Factors Contributing to Drivers' Engagement in the Fatal Five Driving Behaviours". figshare.

https://hdl.handle.net/2134/34812. 


\title{
Bad behaviour or societal failure? Perceptions of the factors contributing to drivers' engagement in the fatal five driving behaviours
}

\author{
Paul M. Salmon ${ }^{1}$, Gemma J. M. Read ${ }^{1}$, Vanessa Beanland ${ }^{1}$, Jason Thompson ${ }^{2}$, \\ Ashleigh J. Filtness ${ }^{3}$, Adam Hulme ${ }^{1}$, Rod McClure, \& lan Johnston ${ }^{4}$ \\ ${ }^{1}$ Centre for Human Factors and Sociotechnical Systems, Faculty of Arts, Business and Law, \\ University of the Sunshine Coast, QLD 4558, Australia \\ ${ }^{2}$ University of Melbourne, Melbourne, VIC, Australia \\ ${ }^{3}$ Loughborough University, Epinal Way, Loughborough LE11 3TU, UK \\ ${ }^{4}$ Ian Johnston Transport Safety Pty Ltd
}




\section{Abstract}

The so-called 'fatal five' behaviours (drink and drug driving, distraction and inattention, speeding, fatigue, and failure to wear a seat belt) are known to be the major behavioural contributory factors to road trauma. However, little is known about the factors that lead to drivers engaging in each behaviour. This article presents the findings from a study which collected and analysed data on the factors that lead to drivers engaging in each behaviour. This involved a survey of drivers' perceptions of the causes of each behaviour and a subject matter expert workshop to gain the views of road safety experts. The results were mapped onto a systems ergonomics model of the road transport system in Queensland, Australia, to show where in the system the factors reside. In addition to well-known factors relating to drivers' knowledge, experience and personality, additional factors at the higher levels of the road transport system related to road safety policy, transport system design, road rules and regulations, and societal issues were identified. It is concluded that the fatal five behaviours have a web of interacting contributory factors underpinning them and are systems problems rather than driver-centric problems. The implications for road safety interventions are discussed. 


\section{Introduction}

The term 'systems thinking' describes a philosophy currently prevalent within safety science that provides expansive theories and methods to support accident analysis and prevention activities (e.g. Leveson, 2004; Perrow, 1984; Rasmussen, 1997). Whilst there are various tenets, contemporary models are underpinned by the notion that safety and accidents are emergent properties arising from non-linear interactions between multiple components across entire systems (e.g. Leveson, 2004). This creates a shared responsibility for accidents that spans all levels of systems, up to and including the government.

In the last decade, the potential utility of applying systems thinking in road safety research and practice has been recognised (Larsson et al., 2010; Salmon and Lenné, 2009; Salmon et al., 2012). There is now a growing consensus that further reductions in trauma may be achieved by applying systems thinking approaches in road safety (Hughes et al., 2016; Larsson et al., 2010; Salmon and Lenné, 2015). This is becoming increasingly relevant given the recent plateau in fatality and injury reductions in many jurisdictions, as well as the fact that in many countries the road toll is increasing. In Australia, for example, from 2015 to 2016 the number of fatalities per 100,000 population increased by $6 \%$. This trend appears to be continuing in 2017 (BITRE, 2017). Systems thinking proponents argue that existing approaches have reached a ceiling in terms of effectiveness and are now experiencing diminishing returns. This is due to the changing nature and increasing complexity of road transport systems (Hughes et al., 2016; Larrson et al., 2010; Salmon and Lenné, 2015). 
The traditional road safety approach involves the " $3 \mathrm{Es}$ " of education, enforcement, and engineering. Examples of this approach can be seen in the interventions used to address the so-called 'fatal five' behaviours known to lead to crashes and road trauma: drug and drink driving, distraction and inattention, failure to wear a seat belt, speeding, and fatigue. Generally, key interventions use education, enforcement, or engineering with the intention of improving road user knowledge and behaviour so that engagement in the fatal five behaviours is reduced. Critics of this approach have focussed on its reductionist basis, whereby the road transport system is artificially isolated from its broader environment (e.g. society), broken into smaller, discrete parts (e.g. road users, vehicles, and roads) and attempts are made to optimise these parts under the assumption that the system will perform better as a result. Many have also argued that there are contributory factors outside of the driver, vehicle and road infrastructure that cannot be addressed through the $3 \mathrm{Es}$ (Hughes et al., 2016; Newnam \& Goode, 2015; Salmon et al., 2012, 2016).

Systems thinking proponents argue that the behaviour of road users is impacted by many other factors and that there is a complex web of interacting factors that lead to drivers engaging in the fatal five behaviours (Salmon et al., 2016). Although some of these factors relate to the individual driver (e.g. personality, risk tolerance, complacency), others likely reside elsewhere in the road transport system (e.g. at the governance and regulatory level). As a result, education, enforcement and engineering will have some impact; however, systemic factors will not be dealt with and so drivers will continue to engage in undesirable behaviours, albeit perhaps to a 
slightly lesser extent. A final important element of systems thinking is that the behaviour of road users can be influenced by factors extrinsic to the road transport system itself. This suggests, for example, that broader societal issues may also be playing a key role in drivers' engagement in certain fatal five behaviours (e.g. drug and drink driving).

In response to calls for a better understanding of the factors that create road trauma, researchers have applied systems theory-based methods to investigate the causes of road trauma and to design new interventions (e.g. Cornelissen et al., 2013; Hughes et al., 2016; Newnam and Goode, 2015; Newnam et al., 2017; Parnell et al., 2017; Salmon et al., 2014, 2016). The overriding philosophy is that the entire road transport system needs to be optimised, not just the individual components acting within it (e.g. road users, vehicles). Whilst initial crash studies have shed new light on the system-wide causes of road trauma, a criticism is that many have focussed only on a single crash event or on existing crash data only (e.g. Newnam and Goode, 2015; Newnam et al., 2017; Salmon et al., 2013). Notably, existing crash data systems have not been able to provide data on crash contributory factors outside of the road user, their vehicle, and the road environment. This has impacted the generalizability and validity of findings and has raised the requirement for further research utilising other data sources (Salmon and Lenné, 2015; Salmon et al., 2016).

This article describes a study designed to go beyond limited accident data and investigate the factors that influence drivers' engagement in the fatal five behaviours. The study involved the use of a driver survey and an expert workshop to 
gather data on drivers' and road safety experts' perceptions of the causes of the fatal five behaviours. The findings from both were then mapped onto a recently developed systems model of the road transport system in Queensland (Qld), Australia (Salmon et al., 2016). The aim was to identify: (a) what factors lead to drivers engaging in each of the fatal five behaviours; and, (b) where these factors reside in the road transport system. The intention was to identify areas of the road transport system outside of drivers, vehicles and the road environment that would benefit from interventions designed to reduce crashes associated with the fatal five behaviours.

\section{Road transport 'systems'}

A contribution of systems thinking-based road safety research has been to provide detailed models of road transport systems. These models depict road transport systems as a series of hierarchical levels comprising multiple interacting stakeholders (Parnell et al., 2017; Salmon et al., 2016; Young et al., 2015). As well as road users, their vehicles their environment and widely known road safety stakeholders, these models also include various other actors and organisations involved in transport system design and operation all the way up to and including the government. A key implication is that crash contributory factors reside across these actors and levels of the system; however, it has been consistently noted that data relating to these contributory factors is sparse (Salmon and Lenné, 2015).

A limitation of existing systems analysis models is that they only describe the road transport system of interest and do not consider where in the road transport system 
crash contributory factors reside. The study described in this article addresses this by building on previous work undertaken by the authors in which a systems model of the Qld road transport system was developed (Salmon et al., 2016). Salmon et al's (2016) control structure model of the Qld road transport system shows the actors and organisations who operate within it along with the control and feedback relationships that exist between them. The present study is an important extension to Salmon et al.'s work as the original model does not include any data on the factors that contribute to road crashes. A key requirement for implementing systems thinking in road safety research is to use systems analysis models to identify crash contributory factors as well as where these reside in the road transport system. Whilst much is known about contributory factors related to drivers, vehicles, and the road infrastructure, few studies have examined contributory factors from the higher levels of the road transport system (Larsson et al., 2010; Salmon et al., 2012; Salmon and Lenne, 2015). The original model presented in Salmon et al (2016) therefore provides a suitable framework to support identification of such factors. The present study involved identifying such factors and them determining which level of the model they are associated with.

Salmon et al.'s original model, including system design and construction and system operations control structures, is presented in Figure 1 and a description of each of the levels from the operations side is presented in Table 1. Within Figure 1, downward pointing arrows and associated text represent control mechanisms imposed by actors and/or organisations at the level above on actors and/or organisations at the level below. For example, police officers at Level 4 impose 
control on the road users at Level 5 via monitoring, enforcement and penalties. Likewise, at Level 1 federal and state parliaments impose control on the level below (government agencies, industry associations, user groups, and the courts) through legislation. Control relationships also exist between non-adjacent levels (as represented by curved arrows). For example, the Department of Transport and Main Roads, situated at Level 3, imposes licensing and registration controls on road users at Level 5.

The dashed arrows pointing upwards represent feedback mechanisms whereby actors and organisations provide information regarding the status of the system to the levels above. For example, 'Government reports' are a feedback mechanism provided by Level 2 (government agencies, industry associations, user groups and the courts) to Level 1 (parliament and legislatures). Crash reports are provided to police officers (Level 4) by road users (Level 5) who were either involved in the crash or witnessed the crash. Feedback mechanisms exist between adjacent levels of the control structure (shown by straight dashed arrows) and between non-adjacent levels (shown by curved dashed arrows). 


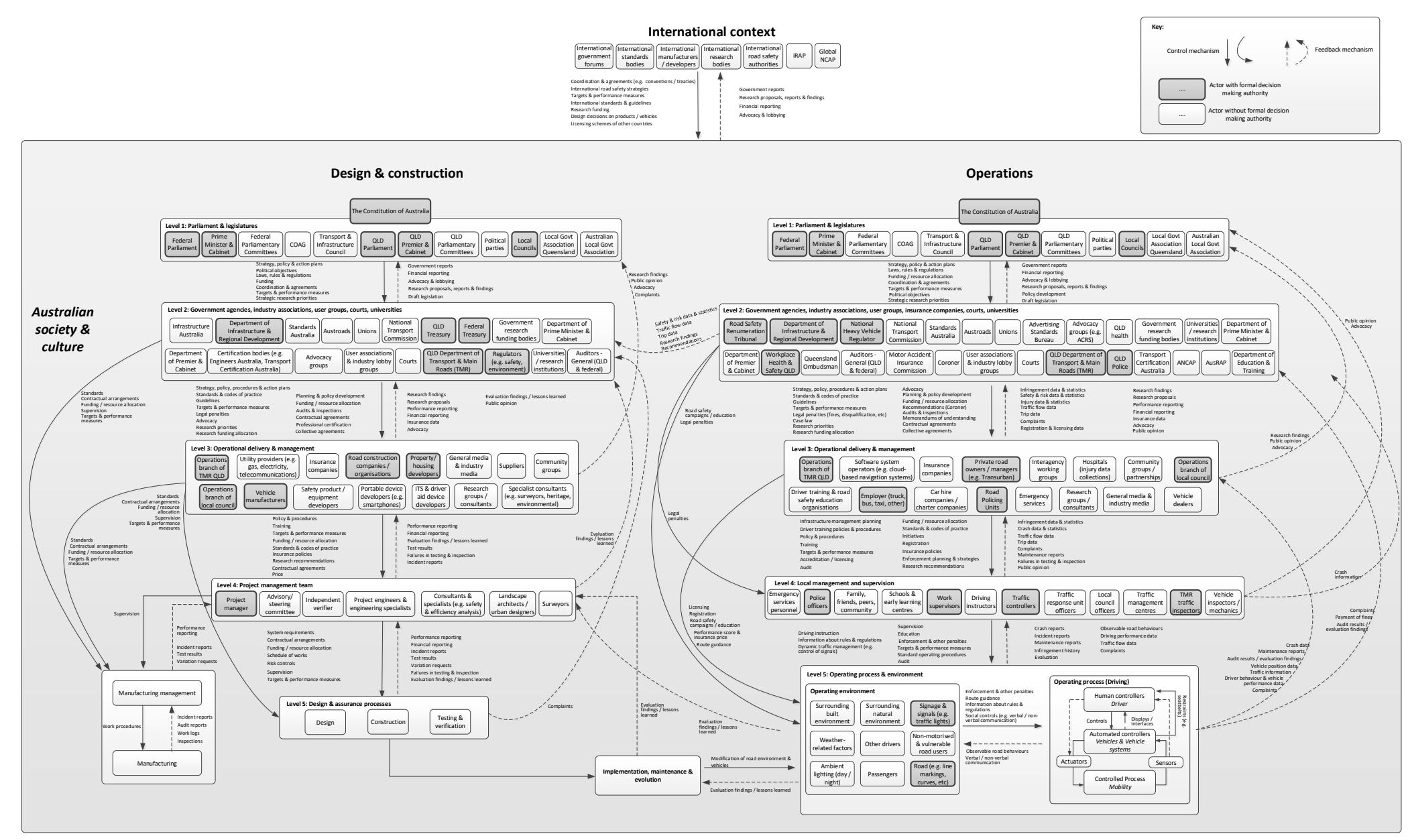

Figure 1. Queensland road transport system operations control structure (Source: Salmon et al., 2016) 
Table 1. Queensland road transport system operations STAMP control structure levels (Salmon et al., 2016)

\begin{tabular}{|c|c|}
\hline Level & Description \\
\hline Level 1: Parliament \& legislatures & $\begin{array}{l}\text { Actors at this level include the state and federal parliaments, Ministers with } \\
\text { transport portfolios, government committees and councils (including COAG - } \\
\text { the Council of Australia Governments) and federal research funding bodies } \\
\text { (such as the Australian Research Council and the National Health and Medical } \\
\text { Research Council). }\end{array}$ \\
\hline $\begin{array}{l}\text { Level 2: Government agencies, user } \\
\text { groups, industry associations, } \\
\text { courts, universities }\end{array}$ & $\begin{array}{l}\text { Government agencies as well as regulators, industry associations and user } \\
\text { groups and the courts reside at this level. Such actors are generally enacted by } \\
\text { legislation or hope to influence the legislatures. A key government } \\
\text { organisation at this level is the QLD Department of Transport and Main Roads } \\
\text { (TMR). }\end{array}$ \\
\hline $\begin{array}{l}\text { Level 3: Operational delivery and } \\
\text { management }\end{array}$ & $\begin{array}{l}\text { The operational delivery and management level includes a range of } \\
\text { organisations who are involved in road transport operations including the } \\
\text { operational divisions of TMR (responsible for driver licensing, vehicle } \\
\text { registration, etc.), as well as employers of professional drivers (such as heavy } \\
\text { vehicle drivers, bus drivers, taxi drivers, etc.). It also includes groups such as } \\
\text { ANCAP (who provides consumer safety ratings of new and used cars), } \\
\text { hospitals (who collect and classify data about injuries following crashes), } \\
\text { research groups and the media. }\end{array}$ \\
\hline $\begin{array}{l}\text { Level 4: Local management and } \\
\text { supervision }\end{array}$ & $\begin{array}{l}\text { This level includes the actors that can directly supervise and/or influence the } \\
\text { driving process (e.g. the Police, parents, friends and peers) as well as actors } \\
\text { such as the emergency services, schools, supervisors in the workplace, traffic } \\
\text { controllers who direct drivers during roadworks, workers in the traffic } \\
\text { management centre and vehicle mechanics / inspectors. }\end{array}$ \\
\hline $\begin{array}{l}\text { Level 5: Operating process and } \\
\text { environment }\end{array}$ & $\begin{array}{l}\text { The operating process for the road transport system is defined as the } \\
\text { interaction of road users with vehicles and vehicle systems. This occurs } \\
\text { through road users manipulating controls within the vehicle and gaining } \\
\text { information about the vehicle's functioning via displays. Also included are } \\
\text { other road users and their vehicles and the road and related infrastructure. }\end{array}$ \\
\hline
\end{tabular}

The control structure model suggests that there are likely multiple interacting factors that the lead to drivers engaging in the fatal five behaviours (related to inappropriate, deficient, or absent control and feedback mechanisms) and that these factors will span all levels of the system. The present study aimed to identify what these factors are and where they reside within the Qld road transport system. These aims were achieved through the conduct of two studies: 
1. Survey of road user perceptions on the causes of each fatal five behaviour. Participants completed surveys designed to elicit their perceptions on why drivers engage in each of the fatal five behaviours; and

2. Road safety subject matter expert workshop. Six road safety experts took part in a workshop designed to elicit their perceptions on the causes of each fatal five behaviour.

The use of both a driver survey and expert workshop was necessary to ensure that comprehensive data regarding the factors influencing driver engagement in each behaviour was obtained. Specifically, the authors felt the use of one approach alone would provide only a limited view. For example, with little appreciation or understanding of what the overall road system comprises, it was felt that drivers would be unlikely to understand the role of wider systemic factors in influencing their behaviour. This is consistent with Leveson's (2004) argument that people have limited process models of the system in which they operate. However, with their day-to-day experience within the system, it was felt that their views would provide valid local examples of the factors that influence driver behaviour. In relation to the workshop, it was felt that eliciting the views of road safety experts with experience in systems thinking research alone may lead to an overemphasis on identifying wider systemic factors as opposed to driver-related factors. The combination of the expert workshop and the driver survey enabled us to build a picture of how the wider systemic factors influence the lived experience of drivers as users of the system.

\section{Study 1 - Driver Survey}


Design

An online voluntary and anonymous survey study was used to gather data on

drivers' perceptions of the factors that influence engagement in each of the fatal five behaviours. A convenience sampling approach was adopted. Formal approval for the study was granted by the University of the Sunshine Coast's research ethics committee.

\section{Participants}

Participants were 316 residents of Qld, Australia, who held a valid full driving licence. A summary of participants' gender, age, time spent living in Qld, and driving experience is presented in Table 2 . The majority of participants were aged between 41 and 70, had over 20 years driving experience, and had resided in Qld for over 20 years.

Table 2. Survey participant demographics

\begin{tabular}{|c|c|c|c|}
\hline Gender & Age & Years lived in Qld & Years driving experience \\
\hline Male 53\% & $18-2516.0 \%$ & $<1$ year $\mathbf{2 . 4 \%}$ & $<1$ year 3.5\% \\
\hline \multirow{6}{*}{ Female $\mathbf{4 7 \%}$} & $26-4918.4 \%$ & $1-5$ years $6.0 \%$ & $1-5$ years $10.4 \%$ \\
\hline & $41-5531.3 \%$ & $6-10$ years $7.9 \%$ & $6-10$ years $8.2 \%$ \\
\hline & $56-7038.2 \%$ & $10-15$ years $9.8 \%$ & $10-15$ years $13.3 \%$ \\
\hline & & $16-20$ years $6.0 \%$ & $16-20$ years $7.3 \%$ \\
\hline & & $20-25$ years $11.7 \%$ & $20-25$ years $11.1 \%$ \\
\hline & & $26+$ years $53.8 \%$ & $26+$ years $45.2 \%$ \\
\hline
\end{tabular}

\section{Materials}

The survey instrument was developed and presented using the Survey Monkey online questionnaire platform. For the purposes of this study, drink and drug driving was decomposed into 'drink driving', 'drug driving (illegal drugs)' and 'drug driving 
(legal drugs)'. Driving without a seatbelt was subdivided into 'driving without a seatbelt' and 'driving without using child restraints'. This yielded the following 'fatal five' behaviours that were included in the survey:

1. Driving whilst fatigued;

2. Drink and drug driving

A. Driving with a Blood Alcohol Content (BAC) above the current legal limit of 0.05 ;

B. Driving under the influence of illegal drugs (including cannabis);

C. Driving under the influence of legal drugs (prescription or over-thecounter medications that impair driving ability);

3. Distraction and inattention;

4. Speeding; and

5. Driving while unrestrained
A. Failure to wear a seat belt; and
B. Failure to use child restraints.

Following demographic questions (e.g. age, driving experience), participants were asked the following four questions regarding each of the eight behaviours (the example below relates to fatigue, however, the wording was the same across the eight behaviours):

1. Have you ever driven while you were (or suspected you were) fatigued? 
2. Thinking about a time that you, or someone you know, drove when they were fatigued, please briefly describe the reason/s for engaging in fatigued driving.

3. In general, what do you think are the reasons why people drive while they are fatigued?

4. What do you think could be done to prevent people driving while they are fatigued?

Open-ended questions were used as the purpose of the survey was to gather data on participants' own perceptions of what factors influence drivers to engage in each behaviour. The study was advertised via a mailing list and on social media including the research centre's Facebook and Twitter pages. The mailing list is one that is maintained by the lead author's research centre and contains details of participants who have participated in our previous road safety research studies. The Facebook advertising feature was also used to advertise the study on the news feeds of potential participants who met the inclusion criteria of living in Queensland, Australia and being aged 18 years or over. Interested participants were directed to the survey via a web link that was open between April-June 2016. Upon completion, participants were invited to enter a prize draw.

\section{Procedure}

Participant responses were subject to content analysis using NVivo 11. Responses were coded using a thematic analysis approach (Braun and Clarke, 2006). This involved coding participants' responses to each question descriptively, and then 
identifying, explaining, and recording patterns and themes within the data. For example, for the question, "In general, what do you think are the reasons why people drive while they are fatigued?" the response "think crashing won't happen to them" was coded as "Complacency / Optimism bias".

To establish the reliability and validity of the coding scheme, inter-rater reliability checks were conducted. This involved the use of a second analyst who coded $20 \%$ of the survey responses for seven of the eight behaviours. Percentage agreement between the two analysts was calculated by comparing the second analyst's coding with the corresponding coding from the first analyst. Agreement between the two analysts ranged from $75.2 \%$ (drink driving) to $91.7 \%$ (driving without using child restraints). Any disagreements were discussed between the analysts and agreed codes were used in the final data set.

The coded items were subsequently mapped by two authors onto Salmon et al.'s (2016) control structure, based on the level at which each factor was deemed to reside. For example, the response "Stupidity / Ignorance" as a reason why drivers drive whilst under the influence of alcohol was added to Level 5 of the model (Operating process: Driving) as it resides within the drivers themselves, whereas the response, "Unreasonable speed limits" was added to the level 3 of the model (Operational delivery and management) as the road rules and regulations are set by actors at this level (e.g. Department of Transport and Main Roads, Local Councils).

\section{Results}


Engagement in the fatal five behaviours

Participants' self-reported prevalence of engagement in each behaviour whilst driving is presented in Figure 2.

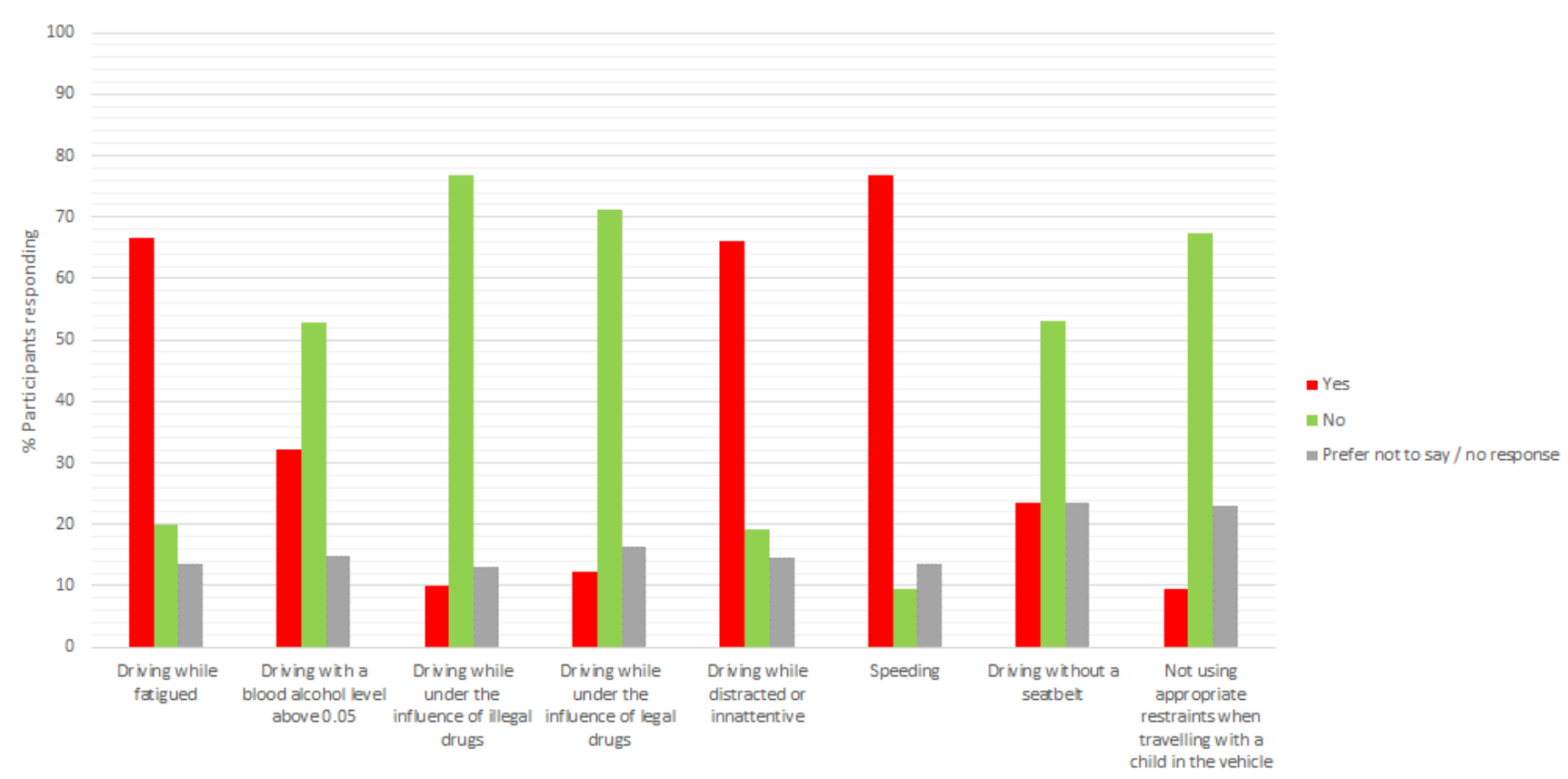

Figure 2. Participants' reported engagement in each of the eight behaviours known to lead to road trauma $(n=316)$.

The highest self-reported prevalence was for speeding, with just over three-quarters of participants reporting having previously driven above the speed limit (76.9\%). Driving while fatigued or distracted/inattentive also had a high prevalence, with approximately two-thirds of participants reporting these behaviours (66.5\% and 66.1\%). Around a third of participants (32.3\%) reported having previously driven with a blood alcohol content of 0.05 or above (the current legal limit in Qld). Almost a quarter of participants reported having previously driven without wearing a 
seatbelt (23.4\%) and almost a tenth reported driving with children who were not appropriately restrained (9.5\%). Around a tenth of participants reported that they had previously driven whilst under the influence of illegal drugs (10\%) or legal (12\%) drugs that can impair driving performance.

Factors leading to drivers engaging in the fatal five behaviours

Questions 2 and 3 asked participants to describe the reasons why they, or somebody they knew, engaged in each behaviour whilst driving and generally what they thought were the reasons why people drove whilst engaging in each behaviour.

Due to the high number of factors reported by participants (as identified via the thematic coding), only those reported by over $10 \%$ of the sample are presented. $A$ summary of these factors is presented Table 3. 
Table 3. Reasons for each behaviour reported by $10 \%$ or more of the survey sample $(n=316)$. Bold percentages refer to the percentage of the sample reporting each reason.

\begin{tabular}{|c|c|c|c|c|c|}
\hline Fatigue & Drink Driving & Drug Driving & $\begin{array}{l}\text { Distraction \& } \\
\text { Inattention }\end{array}$ & Speeding & Restraint Use \\
\hline $\begin{array}{l}\text { Time pressure } \mathbf{2 7} \% \\
\text { Work requirements } \mathbf{1 8 \%} \\
\text { Do not recognise } \\
\text { impaired } \mathbf{1 8 \%} \\
\text { Necessity of driving } \mathbf{1 6 \%} \\
\text { Shift work } \mathbf{1 4 \%} \\
\text { Long trips } \mathbf{1 3} \% \\
\text { Family \& social } \\
\text { expectations } \mathbf{1 0 \%}\end{array}$ & $\begin{array}{l}\text { Lack of understanding of } \\
\text { risks } \mathbf{3 1 \%} \\
\text { Complacency/ } \\
\text { Optimism bias } \mathbf{3 0 \%} \\
\text { Lack of alternative } \\
\text { transport options } \mathbf{2 3} \% \\
\text { Impaired judgement } \\
\mathbf{1 7 \%} \\
\text { Perception that they } \\
\text { won't get caught } \mathbf{1 7 \%} \\
\text { Unaware that they are } \\
\text { over limit 17\% } \\
\text { Social and cultural } \\
\text { influences } \mathbf{1 7 \%} \\
\text { Stupidity/lgnorance } \mathbf{1 5 \%} \\
\text { Necessity of driving } \mathbf{1 1 \%} \\
\text { Short distance/close to } \\
\text { home } \mathbf{1 1 \%}\end{array}$ & $\begin{array}{l}\text { Illegal drugs: } \\
\text { Irresponsible 22\% } \\
\text { Impaired judgement } \\
\mathbf{1 7 \%} \\
\text { Perception that they } \\
\text { won't get caught 16\% } \\
\text { Do not recognise } \\
\text { impaired 15\% } \\
\text { Stupidity/Ignorance 15\% } \\
\text { Addiction 10\% } \\
\text { Legal drugs: } \\
\text { Necessity of driving 16\% } \\
\text { Lack of alternative } \\
\text { transport options 13\% } \\
\text { Do not recognise } \\
\text { impaired 11\% } \\
\text { Complacency/ Optimism } \\
\text { bias 11\% }\end{array}$ & $\begin{array}{l}\text { Mobile phones } \mathbf{4 8 \%} \\
\text { Interactions with } \\
\text { children in vehicle } \mathbf{2 7} \% \\
\text { Passenger interactions } \\
\text { generally } \mathbf{2 3} \% \\
\text { Lack of attention } \\
\text { generally } \mathbf{1 6 \%} \\
\text { Radio/stereo } \mathbf{1 5 \%} \\
\text { Emotions/Stress } \mathbf{1 4 \%} \\
\text { Complacency/Optimism } \\
\text { bias } \mathbf{1 1 \%} \\
\text { Impairment } \mathbf{1 1 \%}\end{array}$ & $\begin{array}{l}\text { Lack of awareness } \\
\text { regarding speed } \mathbf{2 9 \%} \\
\text { In a hurry } \mathbf{2 0 \%} \\
\text { Late } \mathbf{1 9 \%} \\
\text { Unreasonable speed } \\
\text { limits } \mathbf{1 7 \%} \\
\text { Considered non- } \\
\text { compliance } 15 \% \\
\text { Overtaking 13\% } \\
\text { Impatience 13\% }\end{array}$ & $\begin{array}{l}\text { Seatbelts: } \\
\text { Laziness } \mathbf{2 0} \% \\
\text { Stupidity/Ignorance } \mathbf{1 6 \%} \\
\text { Short trip } \mathbf{1 4 \%} \\
\text { Forgetfulness } 13 \% \\
\text { Discomfort } \mathbf{1 1 \%} \\
\text { Child restraints: } \\
\text { Cost of fitting restraints } \\
\mathbf{2 3 \%} \\
\text { Laziness } \mathbf{1 5 \%} \\
\text { Stupidity/Ignorance } \mathbf{1 1 \%}\end{array}$ \\
\hline
\end{tabular}


The majority of the contributory factors reported by survey participants were personal factors relating to drivers, such as stupidity/ignorance, emotions and stress, lack of understanding of the risks, impairment, complacency/optimism bias, perception of not being caught, and laziness. Participants also reported a selection of factors concerned with the wider road transport system and even society generally. These included mobile phones (distraction), social and cultural issues (drink driving), a lack of alternative transport options (drink and drug driving), work requirements and shift work (fatigue), unreasonable speed limits (speeding), and the cost of fitting restraints (failing to use child restraints).

\section{Study 2 - Expert workshop}

Six road safety experts took part in an expert workshop designed to identify factors across the road transport system that influence drivers' engagement in each of the eight behaviours. Potential workshop participants were invited based on their previous involvement in research involving the application of a systems thinking approach to one of the fatal five behaviours in the Australian context. A summary of the participants' experience in road safety is presented in Table 4. The workshop, held over two days, involved reviewing the survey response data for each of the eight behaviours, mapped onto Salmon et al.'s (2016) control structure model, and then identifying additional contributory factors that the experts believed were relevant. First, the two lead authors presented Salmon et al's control structure model to the workshop participants. Taking each behaviour in turn they then presented the survey responses overlaid on the control structure model and asked 
the experts to identify any additional factors that they felt influenced drivers' engagement in the behaviour. This involved a group discussion whereby they worked through each level of the model and asked what additional factors might play a role in influencing drivers' engagement in the behaviour in question. When the experts agreed that a factor was relevant, they discussed which actors or organisations in the model were responsible for the factor in question. When this was agreed upon, the factor was placed on the relevant part of the control structure model using a sticky note. For example, the factor 'inadequate enforcement' was deemed to be the responsibility of the Police and so was placed at level 4 of the model

Table 4. Workshop participant demographics

\begin{tabular}{|lll|}
\hline Participant & Gender & $\begin{array}{l}\text { Year's working in the } \\
\text { area of road safety }\end{array}$ \\
\hline 1 & M & 14 \\
2 & F & 11 \\
3 & M & $45+$ \\
4 & F & 5.5 \\
5 & M & 8 \\
6 & F & 8 \\
\hline
\end{tabular}

The factors that workshop participants felt influenced drivers engagement in each of the behaviours are presented in Table 5 . 
Table 5. Factors identified during the road safety expert workshop that are thought to underpin drivers' engagement in each fatal five behaviour

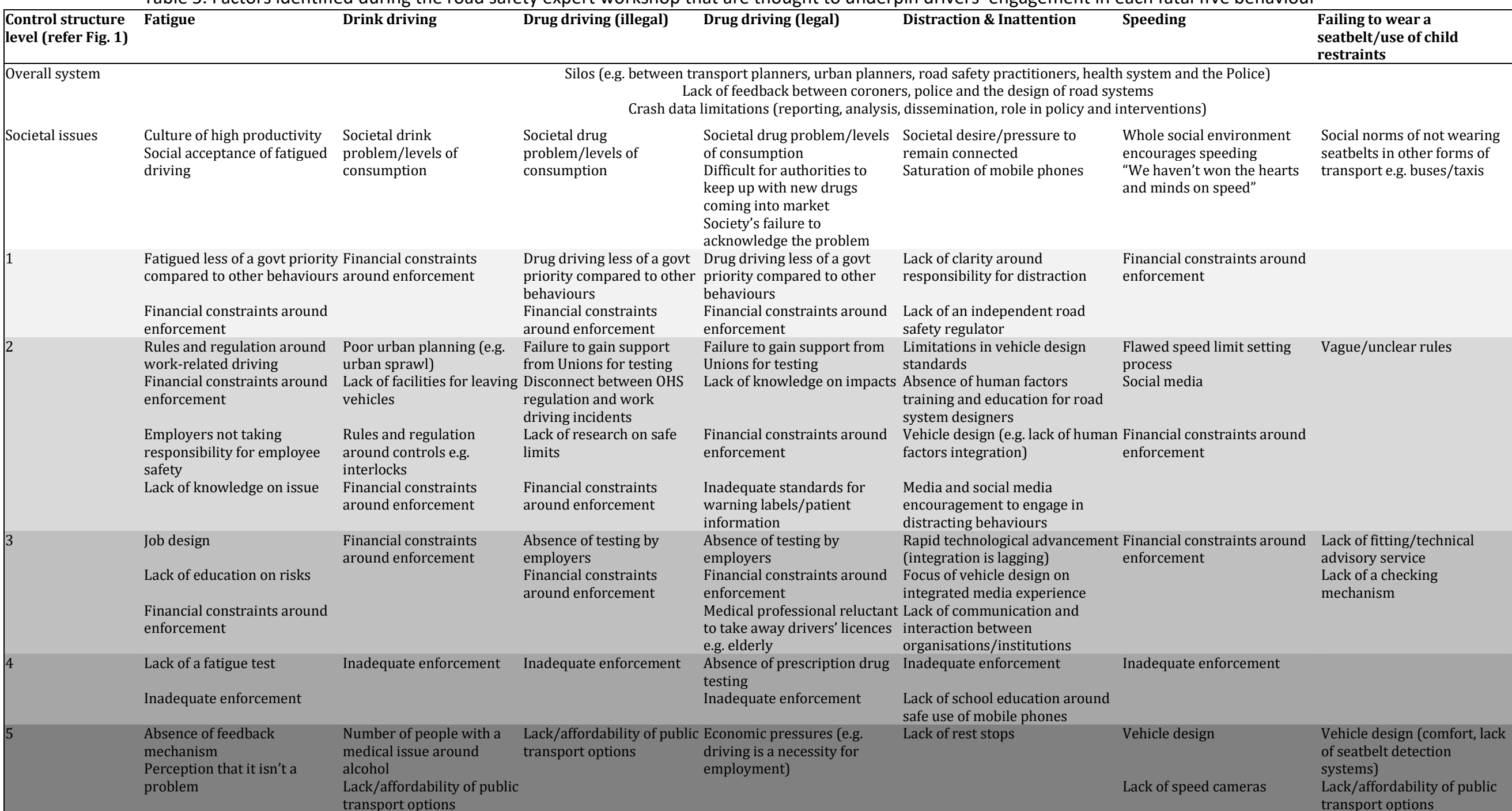




\section{Survey and workshop data mapped onto control structure}

The factors identified in the survey and expert workshop were mapped onto Salmon et al.'s (2016) control structure model. The intention was to identify where the factors reside in terms of at which level of the road transport system they are created. As shown in Figure 3, the majority of factors reported by drivers were related to the lower level of the model (operating process and environment). Conversely, most the factors reported by the experts were deemed to reside at the higher levels of the road transport system (Levels 1-4).

\section{Societal issues}

The expert group and a small number of the survey respondents identified a series of wider societal issues that they felt were impacting driver behaviour. In particular, the experts felt that various societal issues underpin drivers' engagement in drink driving (e.g. societal alcohol consumption levels, alcohol addiction), drug driving (e.g. illegal and prescription drug misuse and addiction, prescription rates), distracted driving (e.g. societal pressure to remain connected, culture of high productivity).

\section{Level 1: Parliament and Legislatures}

At the parliament and legislatures level of the model, the drivers identified the setting of unreasonable speed limits as a factor that results in drivers driving above the speed limit. The expert group identified a lack of clarity around roles and responsibilities for a managing distraction as an issue, suggesting that safety responsibilities outside of the drivers themselves are not well defined - for example, the responsibility of vehicle manufacturers and mobile phone devices to create 
designs that limit the potential for distraction. Financial constraints around enforcement were also identified by the experts as a factor that results in less enforcement on the road and more opportunity for drivers to get away with behaviours such as drink and drug driving and not wearing a seatbelt. The experts also cited the fact that certain behaviours are prioritised over others as an issue. For example, they suggested more well-known and identifiable behaviours (i.e. through roadside testing) such as drink driving are prioritised over more recently emerging and less identifiable behaviours such as driving while fatigued.

Level 2: Government agencies, user groups, industry associations, courts At the government agencies level of the model, the drivers identified the cost of fitting child restraints as a factor that prevents some drivers from using them. The expert group identified various factors at this level, including limitations in vehicle design standards, financial constraints around enforcement, a flawed speed limit setting process (leading to inappropriate speed limits), vague and unclear road rules. An interesting group of factors reported by the experts at this level included factors which facilitate the need to drive. These included poor urban planning leading to urban sprawl and a lack of facilities for leaving vehicles (e.g. overnight). Another group of factors related to the lack of human factors integration in the design of the road environment, vehicles, and devices. Here the experts felt that there is a lack of human factors training for road system designers and poor human factors integration in vehicle design. Finally, factors related to work-related driving were also identified. These included unions resistance to testing (e.g. drugs, fatigue), the 
rules and regulations around work-related driving, and a disconnect between occupational health and safety regulation and work-related driving incidents.

\section{Level 3: Operational delivery and management}

None of the drivers reported any factors at the operational delivery and management level of the model; however, the experts identified ten factors at this level. Again, work-related driving issues featured at this level, with an absence of drug/alcohol/fatigue testing by employees and job design both reported as factors that might influence drivers engagement in behaviours such as driving while fatigued. Also reported at this level were rapid technological advances with which road safety authorities cannot keep pace as well as the focus of vehicle designers on providing drivers with an integrated media experience. Poor support for fitting and maintaining child restraints was also highlighted with the lack of a child restraint fitting services and checking mechanism reported by the experts as impacting the appropriate use of child restraints. Other factors reported by the experts at this level included a lack of education on risks associated with certain behaviours such as fatigue, and financial constraints around enforcement.

Level 4: Local management and supervision

At level 4 of the model the drivers reported four factors (drivers' perception that they will not be caught, work requirements, shift work, and family and social expectations) whereas the experts identified five (inadequate enforcement, absence of roadside testing for prescription drugs and fatigue, lack of school education around safe mobile phone use, and economic pressures on individuals). 
Interestingly, a number of the factors reported at this level relate to the likelihood of drivers being caught when engaging in the eight behaviours. These included drivers' perceptions that they would not be caught which are created by low levels of enforcement and the lack of roadside testing for behaviours such as driving while fatigued or under the influence of prescription drugs).

\section{Level 5: Operating process and environment}

The majority of the factors reported by drivers at level 5 of the model (Operating process and driving environment) were driver-centric and relate specifically to the drivers themselves (e.g. complacency, emotions/stress, stupidity, addiction, impatience). The experts did identify additional factors at this level including vehicle design, a lack of speed cameras, the affordability of alternative transport options, and a lack of safe rest stops. 


\begin{tabular}{|c|c|c|c|c|c|c|c|c|c|}
\hline & $\begin{array}{l}\text { Factors } \\
\text { reported by } \\
\text { drivers via } \\
\text { survey }\end{array}$ & \multicolumn{2}{|c|}{$\begin{array}{l}\text { Additional Factors } \\
\text { reported by } \\
\text { experts via expert } \\
\text { workshop }\end{array}$} & & & & & & \\
\hline \multirow{2}{*}{ Societal issues } & $\begin{array}{l}\text { Social and } \\
\text { cultural } \\
\text { influences }\end{array}$ & $\begin{array}{l}\text { Societal } \\
\text { desire/ } \\
\text { pressure to } \\
\text { remain } \\
\text { connected }\end{array}$ & $\begin{array}{c}\text { Saturation of } \\
\text { mobile } \\
\text { phones }\end{array}$ & $\begin{array}{c}\text { Alcohol } \\
\text { consumption } \\
\text { levels }\end{array}$ & $\begin{array}{l}\text { Alcohol } \\
\text { addiction }\end{array}$ & $\begin{array}{l}\text { Illegal drug } \\
\text { misuse and } \\
\text { addiction }\end{array}$ & $\begin{array}{l}\text { Prescription } \\
\text { drug misuse } \\
\text { and } \\
\text { addiction }\end{array}$ & $\begin{array}{l}\text { Prescription } \\
\text { rates }\end{array}$ & Social norms \\
\hline & $\begin{array}{l}\text { Proliferation } \\
\text { of new drugs }\end{array}$ & $\begin{array}{c}\text { Society's } \\
\text { failure to } \\
\text { acknowledge } \\
\text { problem }\end{array}$ & $\begin{array}{l}\text { Culture of } \\
\text { high } \\
\text { productivity }\end{array}$ & $\begin{array}{l}\text { Social } \\
\text { acceptance } \\
\text { of } \\
\text { behaviours }\end{array}$ & $\begin{array}{l}\text { Social } \\
\text { environment } \\
\text { and culture } \\
\text { encourages } \\
\text { behaviours }\end{array}$ & & & & \\
\hline $\begin{array}{c}\text { Level 1: Parliament \& } \\
\text { Legislatures }\end{array}$ & $\begin{array}{l}\text { Unreasonable } \\
\text { speed limits }\end{array}$ & $\begin{array}{l}\text { Lack of clarity } \\
\text { around roles } \\
\text { and } \\
\text { responsibilitie } \\
\text { s }\end{array}$ & $\begin{array}{l}\text { Financial } \\
\text { constraints } \\
\text { around } \\
\text { enforcement }\end{array}$ & $\begin{array}{l}\text { Certain } \\
\text { behaviours } \\
\text { less of a } \\
\text { priority than } \\
\text { others }\end{array}$ & $\begin{array}{l}\text { Lack of an } \\
\text { independent } \\
\text { road safety } \\
\text { regulator }\end{array}$ & & & & \\
\hline \multirow{2}{*}{$\begin{array}{l}\text { Level 2: Govt agencies, } \\
\text { user groups, industry } \\
\text { associations, courts etc. }\end{array}$} & $\begin{array}{c}\text { Cost of fitting } \\
\text { child } \\
\text { restraints }\end{array}$ & $\begin{array}{l}\text { Limitations in } \\
\text { vehicle design } \\
\text { standards }\end{array}$ & $\begin{array}{l}\text { Poor urban } \\
\text { planning (e.g. } \\
\text { urban sprawl) }\end{array}$ & $\begin{array}{l}\text { Union } \\
\text { resistance to } \\
\text { testing }\end{array}$ & $\begin{array}{l}\text { Rules and } \\
\text { regulations } \\
\text { around work- } \\
\text { related driving }\end{array}$ & $\begin{array}{l}\text { Flawed speed } \\
\text { limit setting } \\
\text { process }\end{array}$ & $\begin{array}{l}\text { Vague/unclear } \\
\text { rules }\end{array}$ & $\begin{array}{l}\text { Lack of human } \\
\text { factors } \\
\text { training for } \\
\text { road system } \\
\text { designers }\end{array}$ & $\begin{array}{l}\text { Inadequate } \\
\text { standards for } \\
\text { patient } \\
\text { information }\end{array}$ \\
\hline & $\begin{array}{l}\text { Lack of } \\
\text { facilities for } \\
\text { leaving } \\
\text { vehicles }\end{array}$ & $\begin{array}{l}\text { Disconnect } \\
\text { between OHS } \\
\text { regulation and } \\
\text { work driving } \\
\text { incidents }\end{array}$ & $\begin{array}{l}\text { Lack of } \\
\text { knowledge on } \\
\text { impacts }\end{array}$ & $\begin{array}{l}\text { Financial } \\
\text { constraints } \\
\text { around } \\
\text { enforcement }\end{array}$ & $\begin{array}{l}\text { Media and } \\
\text { Socialmedia }\end{array}$ & $\begin{array}{l}\text { Vehicle design } \\
\text { e.g. lack of } \\
\text { human factors } \\
\text { integration }\end{array}$ & $\begin{array}{l}\text { Rules and } \\
\text { regulations } \\
\text { around } \\
\text { controls e.g. } \\
\text { interlocks }\end{array}$ & $\begin{array}{l}\text { Inadequate } \\
\text { standards for } \\
\text { waming labels }\end{array}$ & \\
\hline \multirow{2}{*}{$\begin{array}{l}\text { Level 3: Operational } \\
\text { delivery and } \\
\text { management }\end{array}$} & $\begin{array}{c}\text { Rapid } \\
\text { technological } \\
\text { advances } \\
\text { leaving } \\
\text { integration } \\
\text { behind } \\
\end{array}$ & $\begin{array}{l}\text { Financial } \\
\text { constraints } \\
\text { around } \\
\text { enforcement }\end{array}$ & $\begin{array}{l}\text { Absence of } \\
\text { testing by } \\
\text { employers }\end{array}$ & Job design & $\begin{array}{l}\text { Lack of } \\
\text { restraint } \\
\text { fitting/ } \\
\text { advisory } \\
\text { services }\end{array}$ & $\begin{array}{l}\text { Focus of } \\
\text { vehicle } \\
\text { designers on } \\
\text { integrated } \\
\text { media } \\
\text { experience } \\
\end{array}$ & $\begin{array}{l}\text { Lack of } \\
\text { education on } \\
\text { risks }\end{array}$ & $\begin{array}{l}\text { Medical } \\
\text { professionals' } \\
\text { reluctance to } \\
\text { remove } \\
\text { licenses }\end{array}$ & $\begin{array}{l}\text { Lack of } \\
\text { communication } \\
\text { between } \\
\text { organisations }\end{array}$ \\
\hline & $\begin{array}{l}\text { Lack of a } \\
\text { checking } \\
\text { mechanisms }\end{array}$ & & & & & & & & \\
\hline $\begin{array}{l}\text { Level 4: Local } \\
\text { management and } \\
\text { supervision }\end{array}$ & $\begin{array}{l}\text { Unlikely to } \\
\text { be caught }\end{array}$ & $\begin{array}{l}\text { Work } \\
\text { requirements }\end{array}$ & Shiftwork & $\begin{array}{l}\text { Family and } \\
\text { social } \\
\text { expectations }\end{array}$ & $\begin{array}{l}\text { Inadequate } \\
\text { enforcement }\end{array}$ & $\begin{array}{l}\text { Absence of } \\
\text { roadside tests } \\
\text { for } \\
\text { prescription } \\
\text { drugs }\end{array}$ & $\begin{array}{l}\text { Absence of } \\
\text { roadside tests } \\
\text { for fatigue }\end{array}$ & $\begin{array}{l}\text { Lack of school } \\
\text { education } \\
\text { around safe } \\
\text { use of mobile } \\
\text { phones }\end{array}$ & $\begin{array}{l}\text { Economic } \\
\text { pressures on } \\
\text { individuals }\end{array}$ \\
\hline \multirow{3}{*}{$\begin{array}{l}\text { Level 5: Operating } \\
\text { process and } \\
\text { environment }\end{array}$} & $\begin{array}{l}\text { Complaceny } \\
\text { /Optimism } \\
\text { bias }\end{array}$ & $\begin{array}{l}\text { Passenger } \\
\text { interactions }\end{array}$ & $\begin{array}{l}\text { General lack } \\
\text { of attention }\end{array}$ & $\begin{array}{l}\text { Emotions/ } \\
\text { Stress }\end{array}$ & $\begin{array}{l}\text { Impariment/ } \\
\text { Impaired } \\
\text { judgement }\end{array}$ & $\begin{array}{c}\text { Lack of } \\
\text { understanding } \\
\text { of risks }\end{array}$ & $\begin{array}{l}\text { Perception } \\
\text { that wont be } \\
\text { caught }\end{array}$ & $\begin{array}{l}\text { Lack of safe } \\
\text { rest stops }\end{array}$ & \\
\hline & $\begin{array}{l}\text { Unaware/ } \\
\text { Lack of } \\
\text { awareness }\end{array}$ & $\begin{array}{l}\text { Stupidity/ } \\
\text { Ignorance/ } \\
\text { Laziness }\end{array}$ & $\begin{array}{c}\text { Necessity of } \\
\text { driving }\end{array}$ & $\begin{array}{l}\text { Trip length } \\
\text { (Long or very } \\
\text { short) }\end{array}$ & Irresponsible & Addiction & $\begin{array}{l}\text { Do not } \\
\text { recognise } \\
\text { impairment }\end{array}$ & $\begin{array}{l}\text { Perception } \\
\text { that there isnt } \\
\text { a problem }\end{array}$ & $\begin{array}{l}\text { Vehicle } \\
\text { design }\end{array}$ \\
\hline & $\begin{array}{l}\text { Family and } \\
\text { social } \\
\text { expectations }\end{array}$ & $\begin{array}{l}\text { In a hurry/ } \\
\text { time } \\
\text { pressure/ } \\
\text { Late }\end{array}$ & $\begin{array}{l}\text { In-vehicle } \\
\text { devices }\end{array}$ & $\begin{array}{l}\text { Considered } \\
\text { non- } \\
\text { compliance }\end{array}$ & Overtaking & Impatience & $\begin{array}{l}\text { Lack of } \\
\text { alternative } \\
\text { transport } \\
\text { options }\end{array}$ & $\begin{array}{c}\text { Affordability } \\
\text { of } \\
\text { alternative } \\
\text { transport } \\
\text { options }\end{array}$ & $\begin{array}{l}\text { Lack of } \\
\text { speed } \\
\text { cameras }\end{array}$ \\
\hline
\end{tabular}

Figure 3. Driver survey and expert workshop findings overlaid on Salmon et al's (2016) control

structure levels. 


\section{Discussion}

This study was designed to investigate driver and road safety expert perceptions on the system-wide factors underpinning drivers' engagement in eight behaviours known to lead to fatal road crashes. Based on a survey of driver behaviour and an expert workshop, contributory factors were identified and mapped onto Salmon et al.'s (2016) Qld road transport system control structure.

\section{Engagement in behaviours known to lead to crashes}

Over two-thirds of participants reported that they had driven while distracted and fatigued and three-quarters had knowingly driven over the speed limit. This is in comparison with the lower levels of reported engagement in more ostensibly unacceptable behaviours such as drink driving (32\%), driving under the influence of illegal (10\%) and legal drugs (12\%) and not wearing a seatbelt (23\%).

The reported engagement in speeding, driver distraction and driving while fatigued is similar to those found in recent Australian studies. In a survey study of Victorian drivers, $56 \%$ of participants reported exceeding the posted speed limit in one or more speed zones (Stephens et al., 2017). Previous research has also found that around $60 \%$ of drivers report having driven whilst using a mobile phone (Young and Lenné, 2010). In relation to fatigue, a survey study of almost 1000 Australian drivers found that close to $80 \%$ reported that they had previously driven while sleepy, a state related to fatigue (Obst et al., 2011). In a sample of over 1600 New South Wales and Australian Capital Territory drivers, $66 \%$ reported having experienced driving while fatigued/sleepy (Armstrong et al., 2013). These findings suggest that 
speeding, distraction and inattention, and fatigue are the most commonly engaged in behaviours of those known to lead to crashes and trauma in Australia.

The findings indicate that drivers perceive the majority of factors that contribute to drivers engaging in the eight behaviours to be driver-centric (i.e. they relate specifically to driver characteristics). Across the behaviours, the majority of factors reported via the survey related to drivers and aspects of their personality, knowledge and experience, or psychological state. Commonly reported factors included stupidity/ignorance, emotions and stress, lack of understanding of risks, impairment, complacency or optimism bias, and laziness. Although survey participants did report a selection of factors related to the wider road transport system and even society more generally, the findings suggest that drivers believe that engagement in the behaviours is predominantly a driver-centric problem. This suggests that there may be some benefit in educating road users about the broader set of factors that can potentially influence their behaviour. A better understanding of these influences may enable road users to proactively manage certain factors and ensure that they do not have an adverse influence on their driving behaviours.

The factors identified during the expert workshop covered all levels of the road transport system as defined by Salmon et al. (2016). Most relate to issues and conditions within the broader road system and society that were thought to directly or indirectly influence driver behaviour. This set of factors relate to road infrastructure and vehicle design, road rules and regulations, standards, budgetary constraints, the media and social media, public transport infrastructure, research, 
enforcement, work-related driving, and advances in technological capability. These factors point to the role that actors other than drivers play in road trauma and identify areas that could benefit from interventions.

An important finding was the reported role that wider societal problems play in creating the behaviours known to lead to crashes. Workshop participants felt that engagement in certain behaviours is underpinned by societal issues largely beyond the control of road safety stakeholders. For example, driving under the influence of illegal or legal drugs is an emerging road safety problem (Department of Transport and Main Roads, 2016; Horniak et al., 2017; Malhotra et al., 2017; Smyth et al., 2013; World Health Organisation, 2016) that is underpinned by the societal issue of drug addiction. Road safety authorities attempt to manage drug driving through regulation, enforcement, and education campaigns (World Health Organisation, 2016); however, although drug drivers are caught and proceed through the courts on traffic offences, they are not typically rehabilitated through road safety interventions. Further, road safety stakeholders have little control over the wider societal issues that contribute to drug misuse and addiction. As long as the societal issues co-exist with a strong reliance on motor vehicles for transport there will continue to be a flow of drug affected users into the road transport system.

The same principle applies for other fatal five behaviours which, according to the expert group, are underpinned by societal issues. For example, drink driving rates are influenced by increasing levels of alcohol consumption. Engagement in distracting activities while driving is influenced by an increasing societal pressure to 
remain connected through technology. Speeding and driving while fatigued are issues that are exacerbated by increasingly time poor lifestyles and work pressures. Indeed, the requirement to drive a car in the first place is driven by low-density urban form and lack of viable public transport (Stevenson et al, 2016). These findings are mirrored by Hughes et al. (2016) who argue that existing road safety strategies cannot cope with the impact that societal issues have on road safety (Hughes et al., 2016). A clear implication is that road safety strategy and policy needs to consider the broader societal system in which road transport sits.

The findings also provide further evidence that an integrated public health approach is required to achieve further road safety gains. Recent research has demonstrated that an integrated approach to public health, urban planning and transport safety is likely to achieve greater public health and road safety gains than the current 'siloed' approach (McClure et al., 2015). Further, road safety researchers have suggested that a more integrated approach is required to drive culture change (e.g. Johnston, 2010). With drug driving, for example, road safety stakeholders should coordinate their activities with those tackling drug misuse and addiction. In the case of medication and prescription drugs, government, the media, drug manufacturers, pharmaceutical companies, doctors, healthcare providers, road safety authorities and the police should all be working together to tackle drug addiction and misuse and reduce the number of drivers driving under the influence. This is not straightforward, however, as these groups have differing goals, methods and performance indicators. An important first step would therefore be to attempt to integrate their goals and methods into a coordinated approach. This could be 
underpinned by a shared philosophy that drug addiction be treated by all stakeholders as a medical issue. This would involve doctors attempting to reduce prescriptions, addiction and misuse through offering alternative pain treatments or educating patients about the possibility of addiction, monitoring patients, and offering rehabilitation when required. Likewise, police could modify their enforcement approach to offer medical services and treatment (if required) when they apprehend intoxicated drivers. Other stakeholders such as pharmaceutical companies could also work to improve drug-warning labels to educate users on the possibility of addiction and on the dangers of driving under the influence. Without a coordinated approach, road safety-based interventions are likely to only have marginal impacts, and the societal issues will continue to drive unsafe driving behaviours.

\section{Practical implications}

Regarding factors that road safety stakeholders can control, the findings have implications for preventing engagement in the eight behaviours examined. Many of the driver-centric contributory factors identified will continue to be tackled by through standard avenues such as driver education, enforcement and driver training, however, the findings suggest that interventions aimed at the higher levels of road transport systems will also be beneficial. For example, some of the factors relating to driving while distracted suggest that improvements to design standards for both mobile phones and in-vehicle devices are required (Young et al., 2015). Further, improved human factors integration within vehicle design would heighten the consideration of the potential distracting effects of in-vehicle devices. This could be 
achieved through the inclusion of human factors expertise or through providing human factors training to vehicle and device designers. Improved human factors integration could also be driven through regulatory change to require human centred design processes to be used in the development of vehicles and in-vehicle devices. While this is difficult to achieve at a national level given that Australia imports vehicles designed and built overseas, it can be achieved through international regulation and standards in a similar manner to the aviation and maritime industries.

A further implication is that it may be useful for road safety stakeholders to develop multiple integrated interventions that span all levels of the road transport system. This can be achieved by considering how lower level interventions can be driven by changes to the higher levels of the road transport system. For example, in the case of distraction increased education and enforcement at the lower level should be integrated with changes to vehicle and device design standards and processes as well as changes to road safety strategy designed to enable road safety authorities to keep pace with technological change. This integrated network of interventions approach provides a means of optimising the overall road system rather than merely parts in isolation.

The findings also suggest that there may also be a need to consider new approaches to enforcement. Both the drivers and experts reported various factors related to enforcement that facilitates a belief in drivers that they will not be caught when engaging in each of the behaviours. Further, the experts suggested that a key 
challenge lies in reaching the small number of drivers who do not respond to the threat of standard enforcement (i.e. repeat offenders). In the case of drink driving, for example, repeat offenders have been shown to be more likely than those who have not offended to be involved in fatal crashes and fatal hit-and-run collisions with pedestrians, and to have high blood alcohol concentrations when driving (Lapham et al., 2006). Further research is needed to understand the factors influencing the behaviours of these repeat offenders and to design new types of enforcement or initiatives specifically for them. It may be, for example, that stronger controls are required for this group (Salmon et al., 2016).

A final important implication relates to the crash data systems that are currently used in road transport systems. In combination with other studies (e.g. Newnam and Goode, 2015) the findings suggests that there are important crash contributory factors that reside at the higher levels of road transport systems. Despite this, most crash data systems typically only identify contributory factors related to drivers, their vehicles, and the road environment, with little information available regarding less direct contributory factors residing at the higher levels of the system (Salmon et al., 2016). Whilst the present study suggests that there are important factors outside of the driver, vehicle and road environment that play a role in crashes, there appears to be no data available to investigate specifically their role in crashes. The development of systems thinking-based crash data collection and analysis systems is a key future research requirement that has previously been articulated (e.g. Salmon et al., 2016) and is one that is further emphasised through this study. Similar systems have been developed in other domains and have resulted in advances in the 
knowledge base around the contributory factors involved in adverse events (see Salmon et al., 2017).

\section{Study limitations and areas for further research}

This study had some important limitations. First, both the survey and workshop had small sample sizes which potentially impacts the generalisability of the results. Further surveys with larger sample sizes along with a larger group of experts would remove this limitation (e.g. Armstrong et al., 2013; Stephens et al., 2017). A useful future study would be to repeat the current study in all Australian states with larger survey and expert workshop sample sizes. Second, the survey or expert workshop did not seek to identify relationships between different contributory factors. This is an important omission given the systems thinking philosophy that all accidents are caused by an interacting network of contributory factors. A future study should investigate how the different contributory factors identified interact with one another to create road trauma. Third, the extent to which contributory factors differed across participants describing their own engagement in the fatal five behaviours compared to participants describing other drivers' engagement in the fatal five behaviours was not examined. This was beyond the scope of the present study but would be useful to examine in a future study. A final area for further research that was beyond the scope of this study and article is to investigate differences in the factors reported across participants of differing socio-demographic characteristics such as age, gender and driving experience.

\section{Conclusion}


This study has added to the growing consensus that road trauma is created by a web of interacting factors that span all levels of road transport systems. It is concluded that there are a range of diverse factors that potentially influence drivers' engagement in the fatal five behaviours that are known to play a direct causal role in road crashes. Whilst many of these factors reside within the road transport system, wider societal issues also have a key influence on driver behaviour. A consideration of the contributory factors and societal issues identified is urged when developing road safety strategy, policy, and interventions.

\section{References}

Armstrong, K., Filtness, A. J., Watling, C. N., Barraclough, P., Haworth, N. 2013. Efficacy of proxy definitions for identification of fatigue/sleep-related crashes: An Australian evaluation. Transportation Research Part F: Traffic Psychology and Behaviour, 21, 242-252

Braun, V. and Clarke, V. (2006) Using thematic analysis in psychology. Qualitative Research in Psychology, 3:2, 77-101.

Bureau of Infrastructure, Transport and Regional Economics. 2017. Road Trauma Australia-Annual Summaries, https://bitre.gov.au/publications/ongoing/road deaths australia annual su $\underline{\text { mmaries.aspx }}$, accessed $3^{\text {rd }}$ November 2017.

Cornelissen, M., \& Salmon, P. M. 2013. Same but different? Understanding road user behaviour at intersections using cognitive work analysis. Theoretical Issues in Ergonomics Science, 14:6, pp. 592-615 
Department of Transport and Main Roads. 2016. Drugs and driving,

https://www.qld.gov.au/transport/safety/road-safety/drink-driving/drugs, accessed $3^{\text {rd }}$ November 2017.

Horyniak, D., Dietze, P., Lenton, S., Alati, R., Burns, L., 2017. Trends in reports of driving following illicit drug consumption among regular drug users in Australia, 2007-2013: Has random roadside drug testing had a deterrent effect? Accident Analysis and Prevention 104, 146-155.

Howard, E., Sweatman, P., 2007. Road safety culture development for substantial road trauma reduction. In: AAA Foundation for Traffic Safety, 2007, Improving Traffic Safety Culture in the United States - The Journey Forward. AAA Foundation for Traffic Safety, Washington, DC.

Hughes, B. P., Anund, A., Falkmer, T. 2016. A comprehensive conceptual framework for road safety strategies. Accident Analysis and Prevention, 90, 13-28

Johnston, I., 2010. Beyond 'best practice' road safety thinking and systems management - A case for culture change research. Safety Science 48, 11751181.

Lapham, S.C., Ring Kapitula, L., Baca, J.C., McMillan, G.P. 2006. Impaired-driving recidivism among repeat offenders following an intensive court-based intervention. Accident Analysis and Prevention 38 (1), 162-169.

Larsson, P., Dekker, S.W.A., Tingvall, C. 2010. The need for a systems theory approach to road safety. Safety Science 48 (9), 1167-1174.

Leveson, N. G. 2004. A new accident model for engineering safer systems. Safety Science, 42:4, pp. 237-270.Malhotra, N., Starkey, N.J., Charlton, S.G., 2017. 
Driving under the influence of drugs: Perceptions and attitudes of New Zealand drivers. Accident Analysis and Prevention 106, 44-52.

McClure, R.J., Adriazola-Steil, C., Mulvihill, C., Fitzharris, M., Bonnington, P., Salmon, P.M., Stevenson, M., 2015. Simulating the dynamic effect of land use and transport policies on the development and health of populations. American Journal of Public Health 105 (S2), 223-229.

Newnam, S., Goode, N., 2015. Do not blame the driver: A systems analysis of the causes of road freight crashes. Accident Analysis and Prevention 76, 141-151.

Newnam, S., Goode, N., Salmon, P.M., Stevenson, M., 2017. Reforming the road freight transportation system? An investigation of Coronial inquests in Australia. Accident Analysis and Prevention 101, 28-36.

Obst, P., Armstrong, K., Smith, S., Banks, T. (2011). Age and gender comparisons of driving while sleepy: Behaviours and risk perceptions. Transportation Research Part F: Traffic Psychology and Behaviour, 14:6, 539-542

Parnell, K., Stanton, N.A., Plant, K.L., 2017. What's the law got to do with it? Legislation regarding in-vehicle technology use and its impact on driver distraction. Accident Analysis and Prevention 100, 1-14.

Perrow, C. 1984. Normal Accidents: Living with High-Risk Technologies New York: Basic Books.

Rasmussen, J. (1997). Risk management in a dynamic society: A modelling problem. Safety Science, 27:2/3, pp. 183-213. Reason, J., 1997. Managing the risks of organisational accidents. Ashgate, Surrey, United Kingdom.

Salmon, P.M., Goode, N., Taylor, N., Dallat, C., Finch, C., Lenné, M.G., 2017. Rasmussen's legacy in the great outdoors: a new incident reporting and 
learning system for led outdoor activities. Applied Ergonomics 59 (B), 637648.

Salmon, P.M., Lenné, M.G., 2015. Miles away or just around the corner: systems thinking in road safety research and practice. Accident Analysis and Prevention 74, 243-249.

Salmon, P.M., McClure, R., Stanton, N.A., 2012. Road transport in drift? Applying contemporary systems thinking to road safety. Safety Science 50 (9), 18291838.

Salmon, P.M., Read, G., Stanton, N.A, Lenné, M.G., 2013. The Crash at Kerang: Investigating systemic and psychological factors leading to unintentional noncompliance at rail level crossings. Accident Analysis and Prevention 50, 12781288.

Salmon, P.M., Read, G.J.M., Stevens, N., 2016. Who is in control of road safety? A STAMP control structure analysis of the road transport system in Queensland, Australia. Accident Analysis and Prevention 96, 140-151.

Smyth, T., Sheehan, M., Siskind, V., Mercier-Guyon, C., \& Mallaret, M., 2013. Consumer perceptions of medication warnings about driving: a comparison of French and Australian labels. Traffic Injury Prevention 14 (6), 557-564.

A.N. Stephens, A. N., Nieuwesteeg, M., Page-Smith, J., Fitzharris, M. 2017. Selfreported speed compliance and attitudes towards speeding in a representative sample of drivers in Australia. Accident Analysis and Prevention, 103, 56-64 
Stevenson, M., Thompson, J., et al., (2016). Land-use, transport and population health: estimating the health benefits of compact cities. The Lancet, 388 (10062): 2925-2935.

World Health Organisation. 2016. Drug use and road safety: a policy brief.

http://www.who.int/substance abuse/drug use road safety/en/, accessed $3^{\text {rd }}$ November 2011.

Young, K. L., Salmon, P. M. (2015). Sharing the responsibility for driver distraction across road transport systems: A systems approach to the management of distracted driving. Accident Analysis and Prevention, 74, 350-359.

Young, K.L., Lenné, M.G., 2010. Driver engagement in distracting activities and the strategies used to minimise risk. Safety Science 48, 326-332. 